\title{
An Approach to InCREASE THE AgILITY IN Single-ITEM ProduCTION SYSTEMS
}

\author{
AKHAVEI, F. \& KREUZER, P.
}

Abstract: The high variability in single-item and small batch production systems results in complexity in the product development and manufacturing processes. This paper suggests a methodology to raise efficiency and agility in single item production processes. Recently, the increasing application of variant-oriented product modelling led to a rising efficiency in production systems. But deficiency of harmonisation between design and production structures and also traditional and conventional production principles in this kind of production limits the standardization and agility of the design, preparation and planning process. To address this problem, we introduce an approach to restructure the design and production processes and structures in single-item production systems. As a result, we present an integrated model of a production system to minimize circle times in single-item production.

Key words: Single-item Production, Feature based Production, Variant-oriented design, Reference structure model
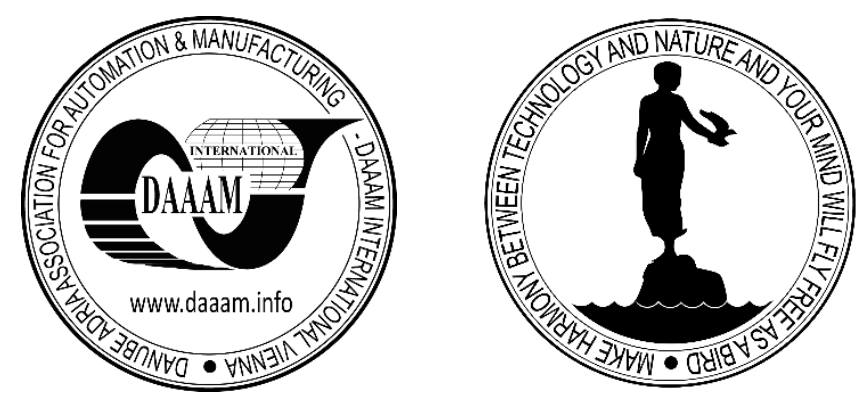

Authors' data: Dipl.-Ing. Akhavei, F.*; Dipl.-Ing(FH). Kreuzer, P.**, *Institute for Production Engineering and Laser Technology, Vienna University of Technology, Getreidemarkt 9, E311, 1060, Vienna, Austria, **Kresta Industries GmbH, Krestastrasse 1, 9433, St. Andrae, Austria, akhavei@ift.at, Philipp.Kreuzer@kresta.at

This Publication has to be referred as: Akhavei, F[arhang] \& Kreuzer, P[] (2016). An Approach to Increase the Agility in Single-Item Production Systems, Chapter 08 in DAAAM International Scientific Book 2016, pp.077-092, B. Katalinic (Ed.), Published by DAAAM International, ISBN 978-3-902734-09-9, ISSN 1726-9687, Vienna, Austria

DOI: $10.2507 /$ daaam.scibook.2016.08 


\section{Introduction}

The high variability in single-item and small batch production systems results in high complexity in the product development and manufacturing processes. The high portion of customer individualization and often deficiency of repetition effect in this kind of production describes a big challenge for agility in production systems. The traditional and conventional production principle in Single-item production also limits the standardization and agility of the design, preparation and planning process. In recent years the construction and application of variant-oriented product development in various industrial sectors has increased enormously. By standardizing and unifying of parts and assemblies in product development it is often tried to reduce the complexity through the reduction of internal variants and diversity. In literature this method is conceived as variant management (Avak, 2007). Variant based product development has specially shown a big advantage in series and mass production such as automotive industry. In single-item production systems compared to series production, the planning and preparation process plays obviously a major role. Therefor the application of modular product development cannot be considered isolated only at design and construction level. To increase the agility in this type of production it is also necessary to eliminate many manual adjustment and adaption activities in design, preparations and planning process. Deficiency of high standardization and harmonisation between design and production structures limits the optimization and automation of the design, preparation and planning process. Unification and harmonization of constructions, planning and productions structure is a strong requirement to optimize the construction preparation process. To achieve this goal, the production structure should be adjusted and harmonized with the construction structure. To dominate this challenge, this work suggests an approach with special consideration on production in single-item production. In this approach, a reference structure model to standardization of all system level is introduced, which realizes an agile production in single-item production system, through automation of preparation and planning process. This reference model makes the system standardization parallel with high level of flexibility possible.

To achieve this, in the first step, the APF concept of Dui, Jiao and Tseng (DUI, Jiao, \& Tseng, 2000) has been integrated with the reference structure concept of Hooshmand, Köhler and Korff-Krumm (Hooshmand, Köhler, \& Korff-Krumm, 2013) and this integrated model has been adapted based on a modular design system. Furthermore, the extension of the reference structure model through the integration of flexible and customer individual components make this methodology suitable for single-item production systems. The production, construction and planning process is also adjusted on basis of this reference structure. The feature technology is responsible for the standardization and establishment of the new structure in the production system. The innovation of this approach compared to the state of the art can be described in following points:

- Development of a reference structure model based on APF concept, modular design and production restriction

- Integration of customer individual components in the reference structure to keep the 
flexibility in single-item production

- Structuring the production processes and harmonization of the production system based on the reference structure model

- Application of feature technology to standardize and establish the reference structure model in the design phase and furthermore, to automate the production preparation process

- Present a holistic approach for optimizing the preparation and production planning process

This methodology is developed on basis of a real case study on the production of containers, reservoir and can also be applied generally in similar metalwork sectors and with some adaption also in many other sectors of single-item and small batch production.

\section{State of the art}

\subsection{Modularity System}

Since Rogers and Bottaci have introduced the concept of modular production system at the end of the nineties (Rogers \& Bottaci, 1997), other scientists have expanded the concept of modular and variant-oriented product development in various fields. For instance, Buck has shown the potential of a modular-based product engineering for optimizing design processes (Buck R. , 2015). He has focused his work on machinery and plant engineering and demonstrated that it is possible to configure varied machineries by modularization and reuse of mechatronic components. This supports the automation of the generation of technical documents. The classification, standardization and modularization of components and assemblies can be used in single item and small batch production accurately as in mass production. Another big advantage of using modular systems in single item production is that it can support a seamless system and process integration (Gansauge L. , 2014). Besides all these advantages, the restriction of flexibility counts as an open criticism of modular and variant-oriented product development. On one side companies should be more flexible and customer-oriented in order to increase their competitiveness, on the other side this contradicts with the high level of standardized and classified production systems (Bliss C. , 2000). This is a reason why modular product development has been applied, in recent years in the mass production, like automotive industry, more frequently than single item and small batch production (Will-Zocholl M. , 2011). Because of this contradiction Ehrlenspiel, Kiewert and Lindemann introduce a $20 / 80 \%$ rule as a solution to meet the flexibility in production systems with a high level of standardization and modularization (Ehrlenspiel K. , Kiewert, Lindemann, \& Mörtl, 2014). According to their view, up to $20 \%$ of each project could be individually designed and adapted. This approach is used in this paper as basis to develop a modular system for single-item production. 


\subsection{Structure harmonization in production systems}

The first step to automate the preparation process is to build a unitary structure between design and production level in the production system. Usually the product or construction structure has been used to create a product configurator and standardize the construction process (Bitter H. , 2010). Actually the construction structure can be defined for a product family. On this base, DUI, Jiao and Tseng describe the structure in product family as APF concept (DUI, Jiao, \& Tseng, 2000). Parallel with this, Hooshmand, Köhler and Korff-Krumm introduce a common organization structure model in the different levels of production system as reference structure model (Hooshmand, Köhler, \& Korff-Krumm, 2013). In their view, the manufacturing processes, construction and other organizational functions should be also standardized and classified in the same structure as modularized products. This structure should be configured in the corresponding IT landscape and dominated throughout the company. Schloter has tried to use modularization in product development for the standardization of other business processes such as sales process (Schloter W. , 2003). Schuh and Lingnau have also shown, that a modular and variant-based product development has very positive effects on accuracy of production planning and can support the harmonization of the organization architecture due to the increase of the repetition effect and information utilization degree (Schuh G. , 1989) (Lingnau V., 1994).

\subsection{Restructuring the production flow and processes}

Beside of the optimization of the product design process, the construction of production processes and logistic flow presents also a major challenge to design an efficient production system in single-item and small batch production. In the actual state of art numerous publications can be found which examine the issue of product and process design in mass production. For example, Eversheim and Schuh have introduced an integrated product and process design based on different scientific approaches (Eversheim \& Schuh, 2005). According to their approach, the production processes and planning structure should be developed due to the manufacturing processes of the products or product structure. In single-item and small batch production it is common that the production processes are established individually according to the product development. Because of the often low standardization the different products have to be manufactured in different processes flow and production structures. However, they point out that this approach lacks direct and fixed leases of procedures and resources and therefor is more suitable for mass production as for individual and small batch production (Eversheim \& Schuh, 2005, S. 247-248). Schoenheit has also introduced a similar approach to Eversheim and Schuh for the design of efficient production processes (Schoenheit, 2013). In his work he has also focused on mass production. Baumberger (Baumberger, 2007) proposes a fixed and standardized production structure for single-item and small batch production. To design the production structure Baumberger adhered to the product structure, and introduce the standardization of product structures as a prerequisite for designing a standardized manufacturing structure. This product structure is provided by standardized and individual modules. Based on this standard structure, the processes can be standardized and depending on personalized components of the product, the 
sub-processes can be developed and integrated into standard processes. Except for the approach of Baumberger, the actual state of the art lacks publications considering the design of production processes in single-item production. Therefor there is a major research potential in this field.

\subsection{Feature technology}

A feature-based design is described as construction of objects that consist of geometric and semantic content (Ising M. , 2001). The features can be described by three classes of attributes. Data attributes contain static information. Rule or method attributes define a specific behaviour of the feature. Relation attributes define interdependencies between semantic features or contain a relation to form features (Göbel \& Teixeira, 2012, S. 169). The Form (shape) and design features are the most known form of features, that are used to accelerate the construction process and the application of repeated components and assemblies (Tietze O. , 2003). Manufacturing, assembly and inspection features are other kinds of features, which can optimize the construction and planning process (Weilguny, 2009). Feature technology can also be applied to unify the structures in construction, planning and production (Gansauge L. , 2014). An effective use of feature technology needs an appropriate IT architecture and system integration. Normally the form and design features are configured in a Product Data Management (PDM) system but some other features like production relevant features may not be necessarily configured in the PDM System. Generally considered, the weight of the PDM system is significantly higher in the IT-architecture of singleitem and small batch production than in mass production (Zhao \& Yu, 2013) (Holl J. , 2003).

\section{Methodology}

\subsection{Reason}

In the state of the art, some solutions have been introduced that can be a part of a new solution to develop an agile und efficient single-item production system. Because most solutions are developed on the basis of mass production, the demand for an integrated and holistic approach especially for single-item production is noticeable. Therefore, the adjustment and adaption of the introduced approaches based on requirements in single-item production is necessary. Beside focusing on the production flow this required approach should support the optimizing and automation of the design and preparation process parallel with the application of modular and variant-oriented product development in single-item production so that the flexibility and customer individuality is maintained. Therefor this new approach is an extended, combined and also application-oriented tool with focus on single-item production.

\subsection{Development of reference structure and reference process model}

The first step to increase the agility in single-item production systems is the elimination of manual adjustment and adaption activities in design, preparations and planning process through automation. The harmonization of construction, planning and productions structure is also required to achieve this goal. To realize this, the definition 
of a common structure model for all levels of the production system is necessary. In this paper this common structure is developed based on the concept of Hooshmand, Köhler and Korff-Krumm and called reference structure model. This structure model is also the basis of the reference process model in production. To define the reference structure model. the restrictions in product development and restrictions in manufacturing and planning are considered simultaneously. To standardize and support the new reference structure variant-oriented design and feature technology should be used. The first step to develop the modular system is establishing the product family.

A product family is a grouping of products which have similarities in resource usage, design, manufacturing process and facilitates planning in aggregate level (Simpson, Jiao, Siddique, \& Hölttä-Otto, 2013). Members of a product family can belong to one and only one product family. It is also possible to plan based on the planning percentages and effectivity of the product family members (Simpson, Jiao, Siddique, \& Hölttä-Otto, 2013). According to the definition of product families, the product or module variants should be established in each product family. For the definition of product variants in a product family the technical and production-related traits are to be respected. The APF-concept is another outcome of product family. In the single-item production, the products can be configured with support of variantoriented assemblies and components on the basis of the APF. Although, the products should have the capability of customer individual customizing and assembling in some levels of their APF. This extension makes the application of APF also possible in single-item production. In this approach APF has been also used as reference structure and process model to harmonize the structure in all levels of the production system.

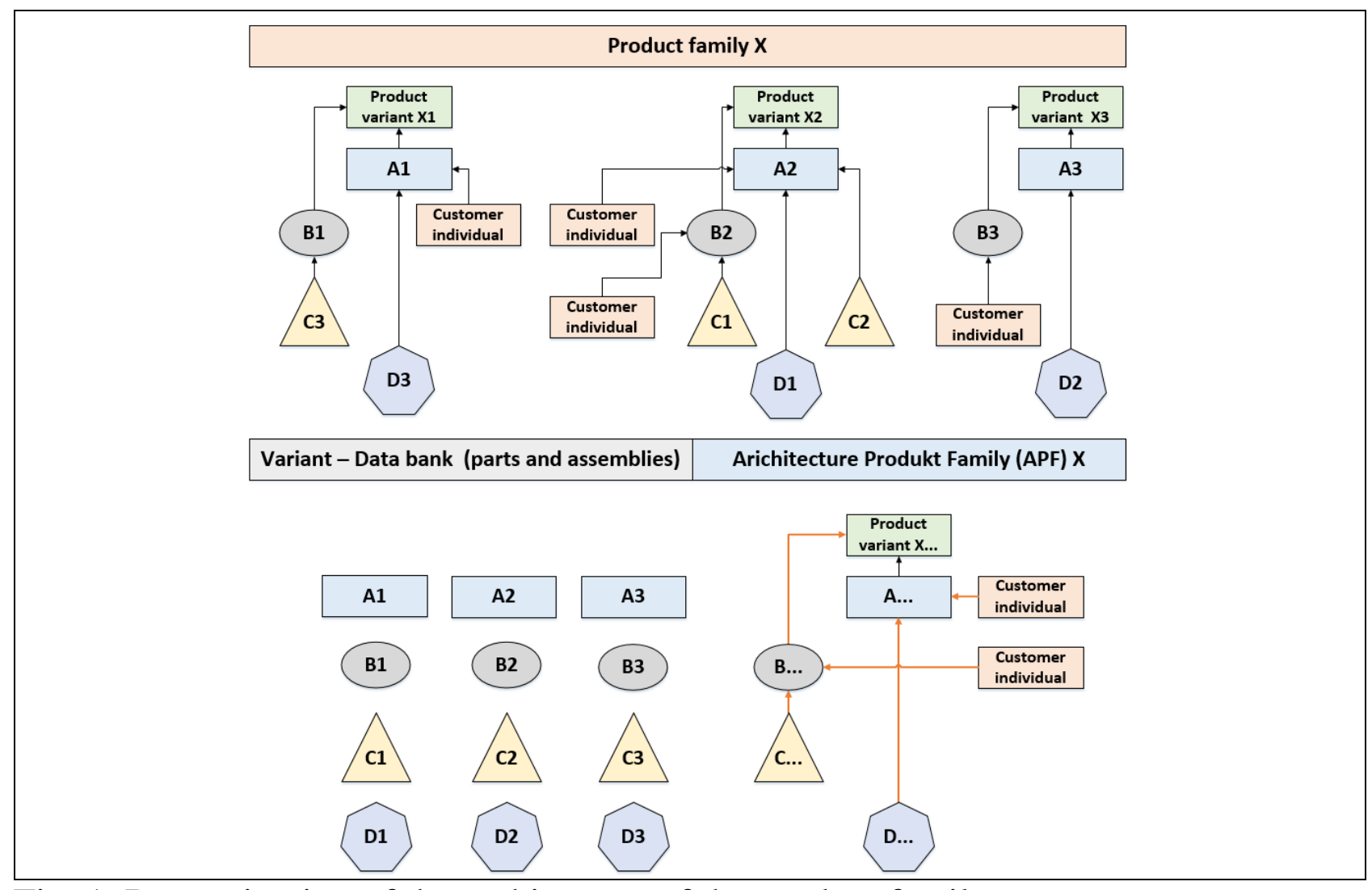

Fig. 1. Determination of the architecture of the product family 


\subsection{Restructuring the production processes}

Due to the often large product range and the accompanying necessary flexibility in single-item and small batch manufacturing, the design and standardization of production processes describe a big challenge. The known methods for process standardization and the design of efficient production processes are often developed based on series and mass production and their application in single-item and small batch production is very limited. A flow production describes the perfection of processoriented manufacturing. However, immediate and permanent assignments of processes and resources between the products are strongly required to design a flow production. Therefore, the usage of the flow production principle is very limited in single-item and small batch production (Eversheim \& Schuh, 2005, S. 247-248). Because of this limitation, most single-item and small batch manufacturers apply a conventional or workshop production principle. This is one of the main reasons for the low utilization rate of information in single-item and small batch production compared to mass production. Due to the high flexibility requirements for single-item and small batch manufacturers a complete application of flow production principle is impracticable in single-item production, but a hybrid production system with a wider standardization range and process flow than workshop production can improve the efficiency in single and small batch production enormously. To develop this hybrid production principle, Baumberger's approach has been applied as basis (Baumberger, 2007). In his methodology Baumberger proposes a fixed and standardized production structure for single-item and small batch production. Through this method, the products are developed and produced individually defying a standardized procedure and structure. In this work this standard structure is called reference process model. The APF concept (DUI, Jiao, \& Tseng, 2000) can be applied as a reference process model as well as a main structure to realize the Baumberger approach in single-item production. By applying the APF concept for the development of the production structure, the constructions and productions structure will be harmonized. Also by design and development the productions structure and manufacturing process is required to consider the manufacturing and technological limitations. If the integration of different product families in the same process architecture is not possible or the product families do not have much in common with each other, it is better to produce them on separate production flows and processes.

Considering the approach of Baumberger, Eversheim and Schuh, the design of manufacturing processes through a hybrid system with fixed assignments of operations and partly flexible work processes is a very good solution to structure the production in single-item and small batch production. In this approach a fixed reference process model and logistics process flow is determined on the basis of the APF. The manufacturing processes for standardized modules, components and assemblies are defined as standard manufacturing processes with the standardized process flow. These manufacturing processes can be standardized in the highest level and can be viewed as supply processes (work stations) for the flexible pre-assembly and assembly processes. In the upper positions of APF (and parts list) and where a high degree of process flexibility is needed in single-item production system, the production processes are designed with the flexible process flow. In other words, the flexible pre- and final 
assembly processes are supplied by standardized supply processes. In a single-item production system it is always necessary to have some production process and work station as a flexible process for the $100 \%$ new customer individual assemblies and components. This work stations are called conventional work stations and are integrated in the standard process expiration. The methodology can be introduced as a hybrid group production principle and strongly supports variant-oriented product design in the production level. In this approach, the products can be manufactured customer individually, despite a high degree of standardization. Thus, the production cycle time is considerably reduced and the degree of materials flow in the production is increased significantly. Because of this methodology, the production structure corresponds exactly to the design structure and the structure harmonization in the production system can be realized.

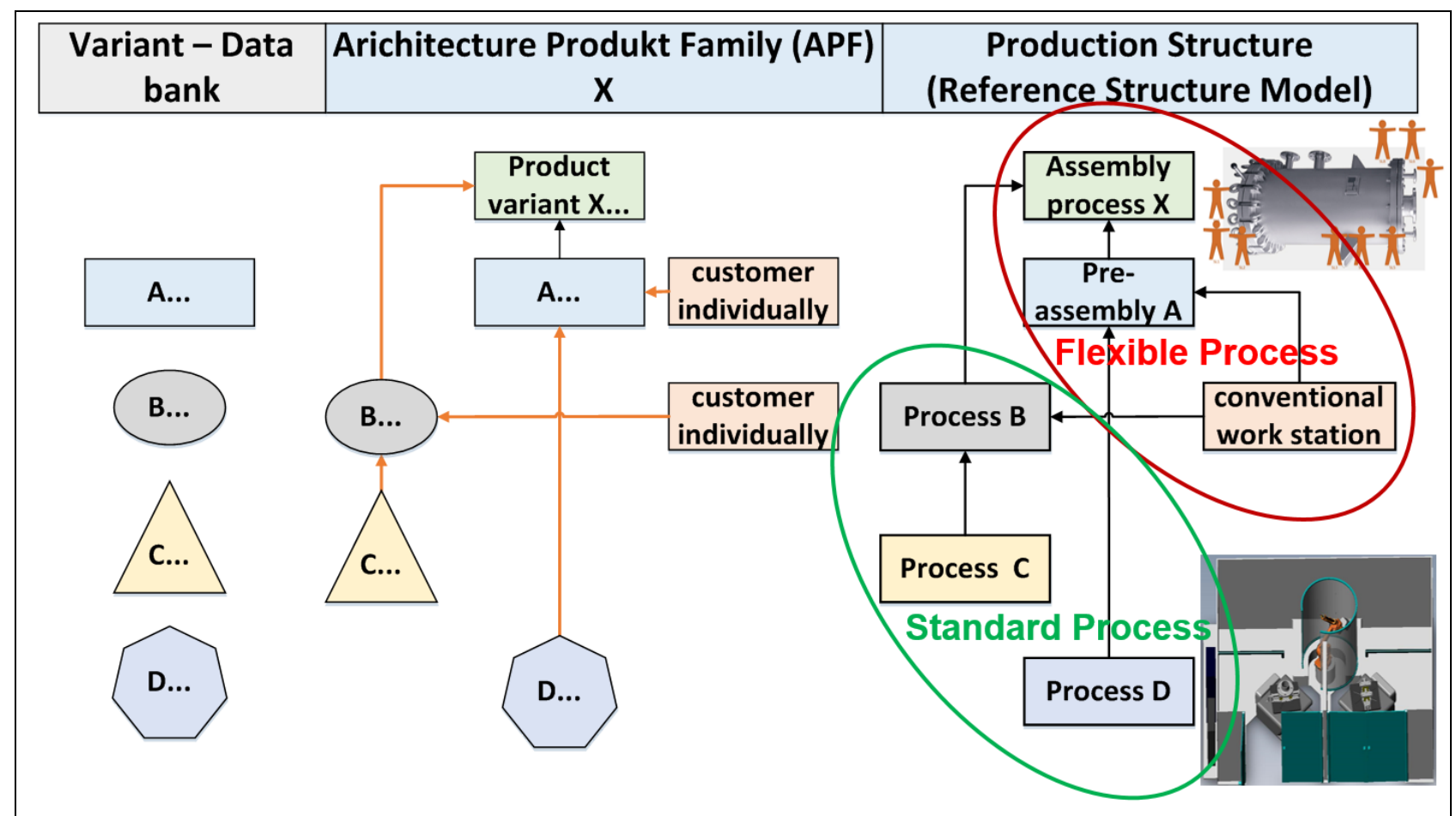

Fig. 2. Developing the production structure based on the reference process model

\subsection{Feature technology to support the modularity system}

Feature technology can be used to establish and standardize the reference structure model in all planes of the production system after defining APF in the product family. To standardise the reference structure model and develop a variant-oriented product design the form and design feature, manufacturing feature and assembly feature should be used. The form feature is defined by analytics surfaces such as planes, cylinders and so on, or in high level holes, ribs, slots, or blending. These features have become popular in mechanical engineering and are now accessible in most of CAD software (Tichkiewitch, Tollenaere, \& Ray, 2010). The form feature is applied to save the geometrical assemblies and components in variant database. The standardized assemblies and components can be saved in principle both only with their form and geometry, independent from their dimension through parametric construction. This depends admittedly on the branch of industry and kind of product family. 
Manufacturing feature as well as assembly feature are used for establishing the reference model structure and supporting the automation of preparation process. Manufacturing feature is defined as a collection of related geometric elements which correspond to a particular manufacturing method or process (Shah, Mäntylä, \& Nau, 2013). The assignment between manufacturing features and knowledge is realised through this manufacturing process model. Manufacturing feature plays a significant role to automate the creation of the work plan. Due to the structural harmonization in the production system, the process mapping logic is provided on the basis of the reference structure model in the product family. The manufacturing features can be configured in the PDM or ERP system. However, it should be possible to assign the components and assemblies as required manually to other processes. An assembly feature assign various form features of different work pieces and describes the assembly and the necessary assembly steps of a component. This includes the presentation of the installation conditions and the joining process (Tietze O. , 2003). In this approach the assembly feature is responsible to standardise and establish the APF as construction structure. To achieve this goal, the APF should be configured in the PDM system through assembly feature as product family configurator.

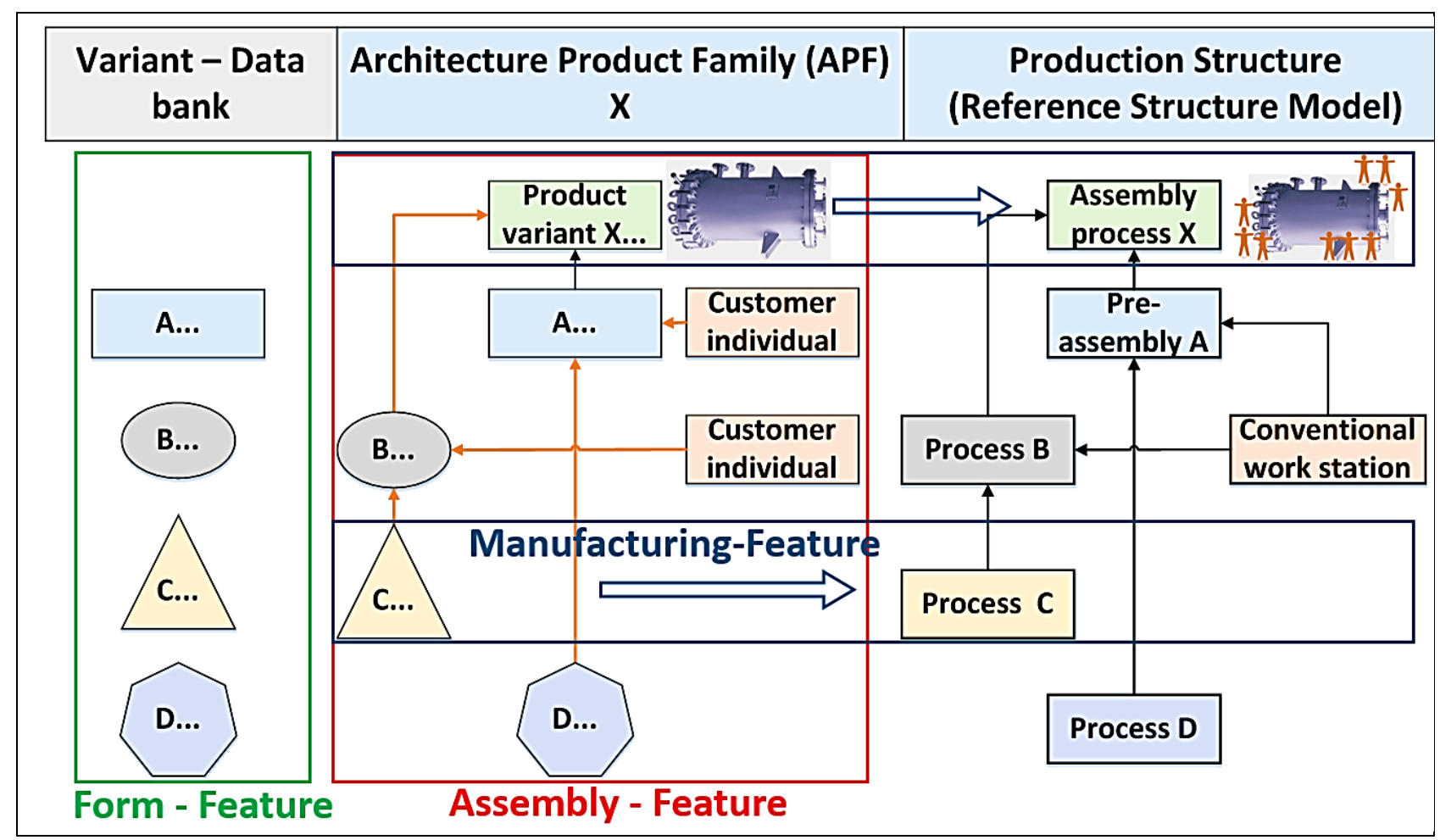

Fig. 3. Form, Assembly and Manufacturing Features

\subsection{Structure harmonization in a production system based on the reference structure model}

In single-item production systems structure harmonization is realized through the standardization of product development based on APF and the setup of the planning and production structure based on the reference structure model. APF, reference structure model and reference process model are exactly the same structure. 
The feature technology supports the standardization and establishment of new structures in production systems. Features will be also enhanced by new knowledge of various products. APF must be standardized through assembly-feature as construction structure in product development. This construction structure should be supported and provided from the variant-oriented parts and assemblies in the variant database. The costumer individual components can also be constructed and integrated in the preplanned position of APF. Thus it is assured that the reference structure model is observed in the constructor phase. After setup of the production process and logistic flow based on the reference process model and the configuration of production planning on the basis of the new structure, the reference structure model is standardized in all levels of the production system. In other words, the construction, production planning and process flow in production will be shaped on the basis of the same structure and the production system is structural harmonized. The integrated construction parts list (BOM, Bill of Material) and production parts list (MBOM, Manufacturing Bill Of Material) is the product of the structure harmonisation in the production system. This reference parts list corresponds also with the reference structure model and reference process model. As mentioned, the application of manufacturing features assigns each component and assembly to the related production process and work station. The three described features in the constructions and preparations phase, enable the integration of parts lists and work plans and automate the creation of this document in single-item production systems. The process and setup time can be filled manually at the first step and probably automatically in future through time-features. This approach allows to use the reference parts list for the procurement, planning and production at the same time.

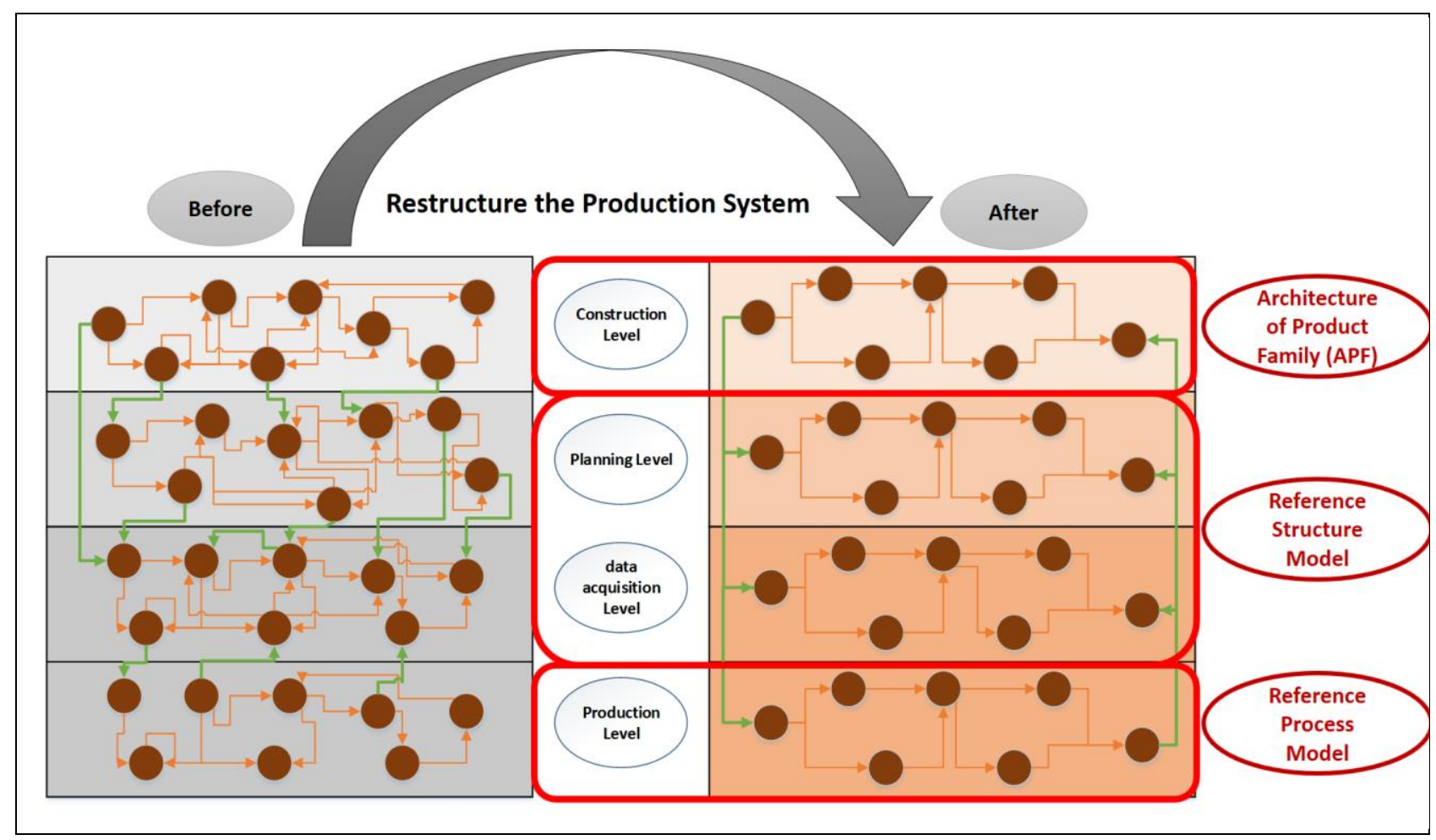

Fig. 4. Structure harmonisation in production system based on APF 


\subsection{IT architecture}

Modern product development systems (PDM) provide designers extensive design possibilities in product development. The feature technology also enables an effective establishment and operation of the variant-oriented design in PDM systems. An effective use of the PDM system is highly dependent on the system configuration.

The introduced features have to be configured in a software landscape. In our approach, the form- and assembly-features should be composited in a PDM system. The parts list is created in the PDM System too. On the other side the structure of production planning, controlling, cost accounting and production data acquisition should be adapted in an ERP system based on the reference structure model. Normally the information about the production process and work stations are saved and administrated in the ERP system. Therefor it probably would be suitable to configure and apply the manufacturing feature in the ERP system.

\section{Case study}

The described approach is realized in a real company to manufacture containers and reservoirs. At the first step the resulting APF is defined and standardized as product configurator through assembly feature in the PDM system. The standardized assemblies and components have been also saved through the form feature in the variant database. In this case study, it was required to save the assemblies and components only with their forms and independent of their dimensions to assure the flexibility in the design and production of containers. Their dimensions are defined parametric (fig. 7). Due to the adjustment of the production system from a full conventional form of production and a manually construction based on 2D to the new production system based on the described approach, the total improvement was enormously. In the first step the design and preparation time for a comparable project was reduced by $35 \%$ as the result of application the variant-oriented design. According to the other comparable studies in state of the art and their results (Bitter H. , 2010), the improvement in production system is legitimated and for the next steps an even bigger improvement is expected.

\begin{tabular}{|l|c|c|}
\hline & Design and preparation time (pro constructor) & Improvement \\
\hline before & 8,5 hours & \multirow{2}{*}{$35 \%$} \\
\hline after & 5.5 hours & \\
\hline
\end{tabular}

Tab. 1. Improvement of design and preparation time.

In this case study, "Inventor" CAD system and "Vault" PDM system have been applied. The form and assembly features are configured in "Vault". Through this approach and the reference parts list is created automatically after the construction with the suitable structure (fig. 5) for planning and production. After importing the parts list in the ERP system, the parts list positions are assigned to the related production processes automatically trough manufacturing feature. In this phase, only the process times must be filled manually. After that, the parts list can be used for production planning without any further adjustment. Because of the suitable structure of the 
Akhavei, F. \& Kreuzer, P.: An Approach to Increase the Agility in Single-Item Pro... reference parts list, the specific parts list and the drawing for every work station is also created in ERP system automatically.

Very interesting effect of this approach has been showed in production. Because of the standardization of the process flow and work stations in the production, the production process became more efficient and the production can be planned more accurate. The production orders can be also paralleled and the production data acquisition became more precise. This situation also supports a more accurate cost estimation for new projects. After running this approach, the average cycle time in production is reduced approximately by $25 \%$. This result has been measured based on the average cycle time of 5 comparable projects before and after the application of this approach. Additionally, the new production structure prepares an optimal base to improve the work station and logistic flow continuously.

\begin{tabular}{|l|c|c|}
\hline & Production cycle time & Improvement \\
\hline before & 15 days & \\
\cline { 1 - 2 } after & 11.3 days & $25 \%$ \\
\hline
\end{tabular}

Tab. 2. Improvement of production cycle time.

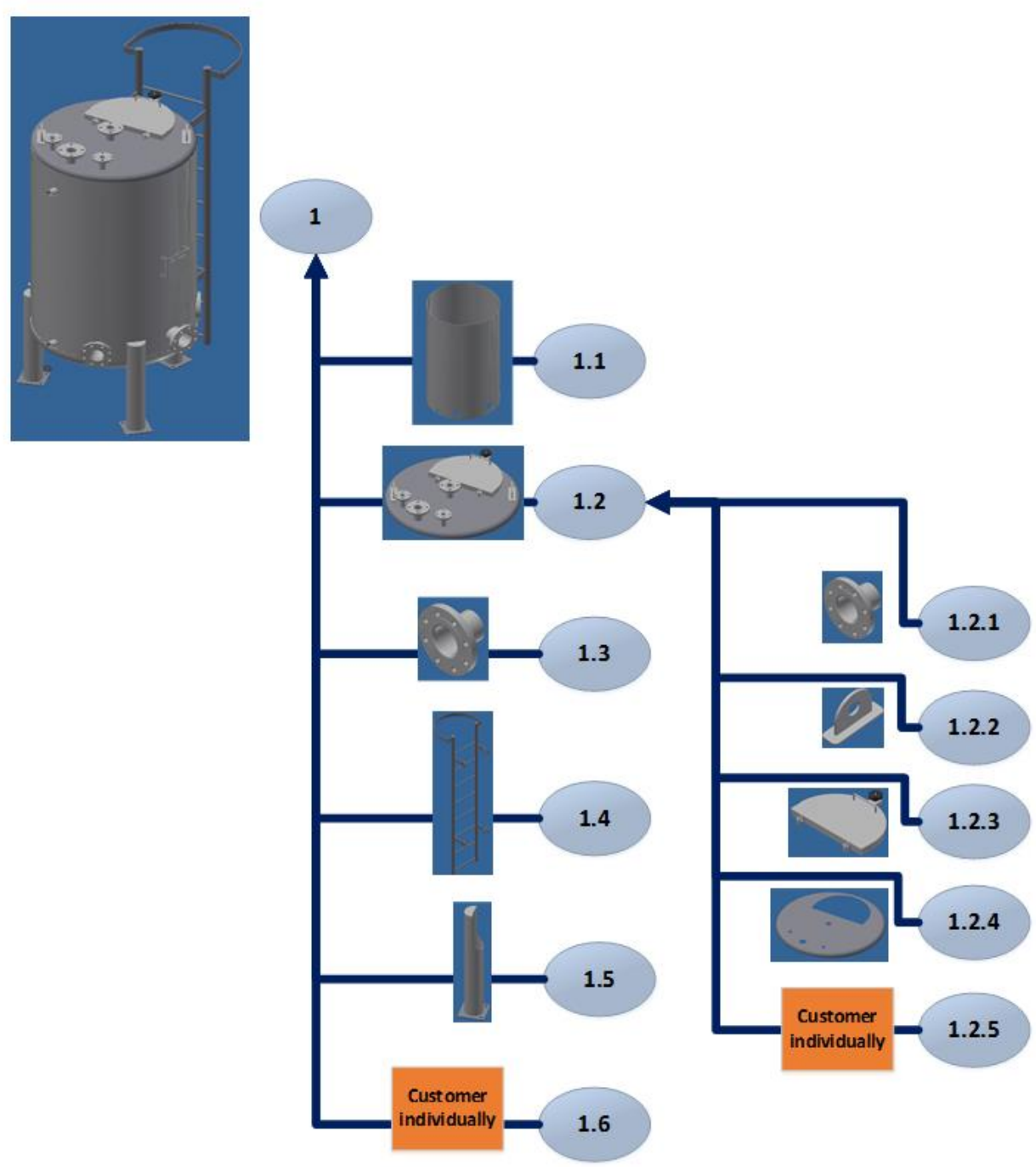

Fig. 5. Structure of the reference parts list 


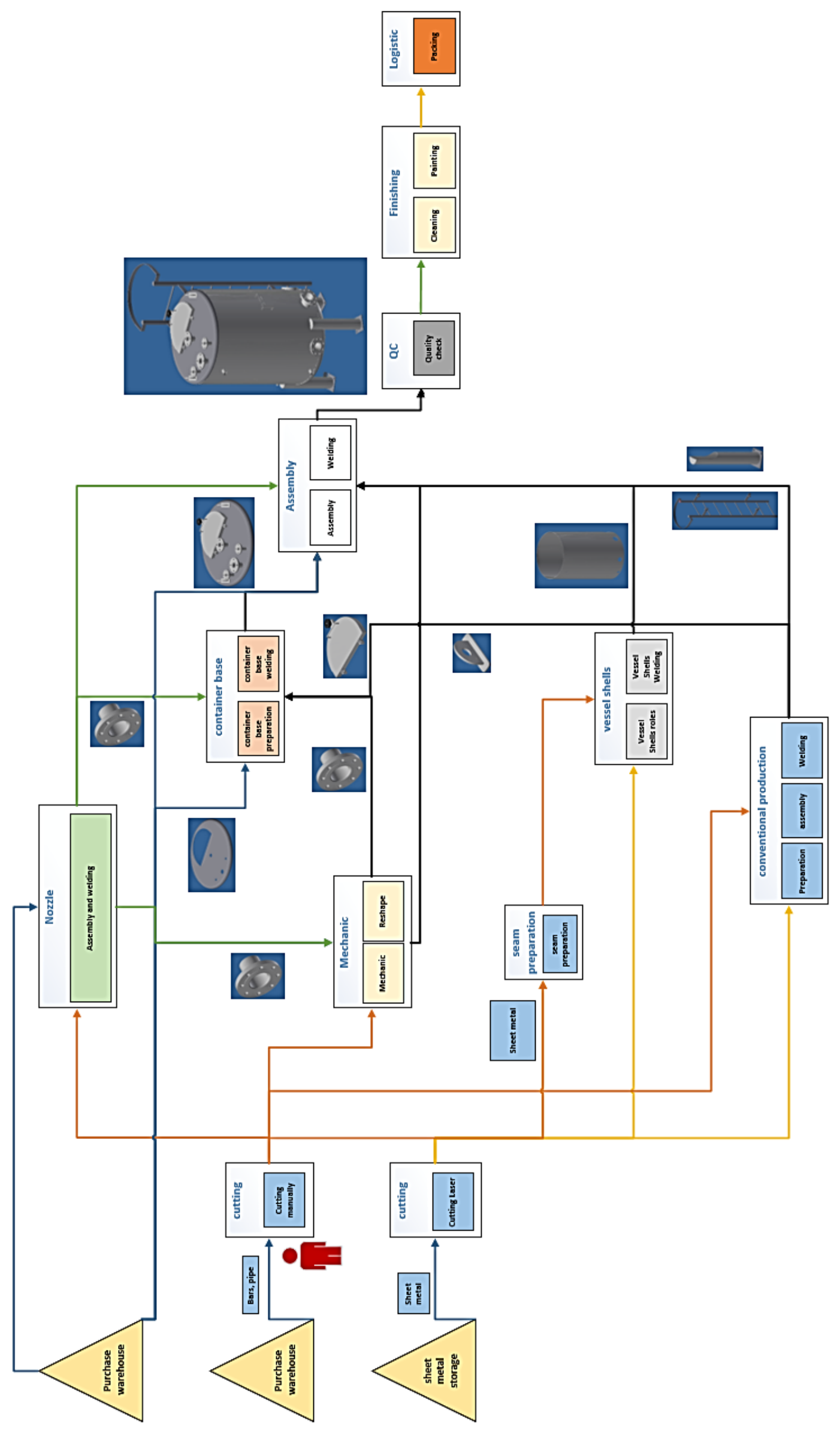

Fig. 6. New production structure for container production 
Akhavei, F. \& Kreuzer, P.: An Approach to Increase the Agility in Single-Item Pro...

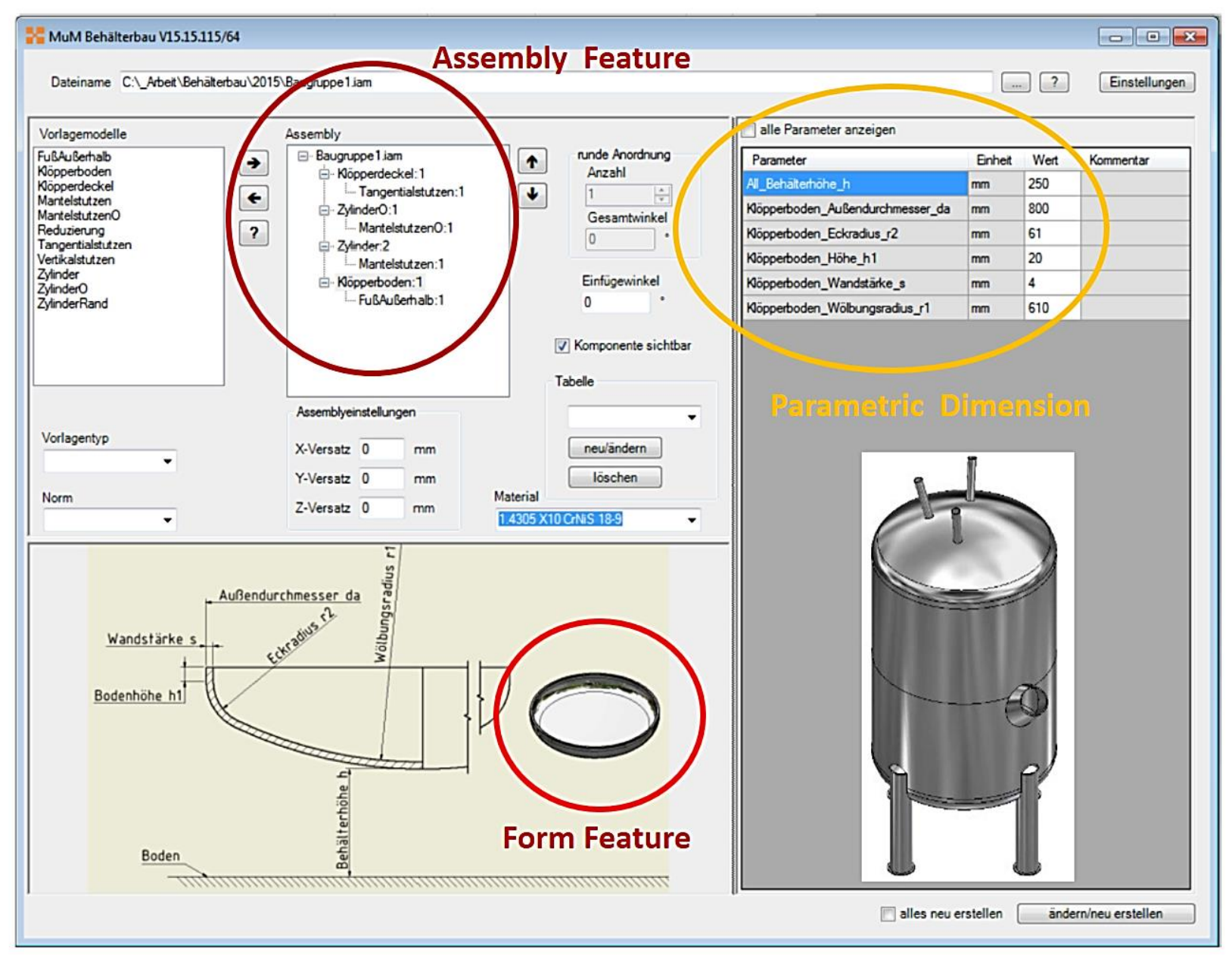

Fig. 7. Configuration of the methodology in the "Vault" PDM System

\section{Conclusion}

In this paper we introduced a new approach to reduce the total cycle time and increase the agility through harmonizing the structures in the single-item production system. Often is the challenge in single-item production, that due to isolated consideration of variant based modelling only in design tier and parallel a conventional production structure, the preparation and planning process is very costly. In this work, we introduce a standardization approach to optimize the preparation and planning process based on development and application of reference structure. Through implementation of this reference structure the different levels of system are structured uniformly and the creation of parts list and work plan is automated. The feature technology is also applied to implementation and standardization of this approach.

After application of the new system, many manual adjustment and adaption activities in the preparation process, like the adjustment of the parts list, the preparation of the production parts list (MBOM), the process flow planning and the adaption of the work plan, have been eliminated, the production cycle time became shorter and the reaction time to the customer's order has been reduced. After implementation of this approach in a real production system, the design, preparation and planning process is improved about $35 \%$ and the cycle time is reduced about $25 \%$. The manual determination of the process time in production planning, is yet the costliest part of the 
preparation process. Therefore, the next step is developing an approach to automate the process time determination based on introduced reference structure. The goal in the next three years is the reduction of design and preparation time to 1,5 hours and production cycle time to 7 days. This goal can be achieved because of following reasons:

- More standardisation in design and production process

- Learning effect by staff

- Bigger form feature library

- Optimization of system configuration

\section{Implications / Consequence}

This Work is a result of research project at Vienna university of technology and this approach is implemented in a real company. At the beginning of the project, some designer meant that so strong standardization in production system, limits the flexibility in single-item production system. But the development and implementation of this approach has shown, that the combination of flexibility and standardization is possible. Especially the modern industrial information systems support the application of this method enormously. After implementation of this approach in production system, a high level of standardisation and synchronization between all company departments was considered. This project was developed to optimize the chemical plants production and in this sector the complexity of design and production is compared to mechatronic systems not high. But the authors think that through adaption and implementation of new features, this approach can be also applied in other sectors of single-item production.

\section{References}

Avak, B. (2007). Variant management of modular product families in the market phase, ETH Zurich

Baumberger, G. C. (2007). Methoden zur kundenspezifischen Produktdefinition bei individualisierten Produkten, München, Technischen Universität München

Bitter, H. (2010, 2). Kundenindividuell geht auch wirtschaftlich, CAD-CAM Engineering Report

Bliss, C. (2000). Darstellung und Kritik des bestehenden Komplexitätsmanagements, Wiesbaden, Gabler Verlag

Buck, R. (2015). Entwurfsmuster für den Aufbau von Baukästen für das Funktionale Engineering, Fraunhofer Verlag, Stuttgart

DUI, X.; Jiao, J.; \& Tseng, M. M. (2000). Architecture of product family for mass customization, ICMIT 2000, (pp. 437-443)

Ehrlenspiel, K.; Kiewert, A.; Lindemann, U.; \& Mörtl, M. (2014). Kostengünstig Entwickeln und Konstruieren: Kostenmanaement bei der integrierten Produktentwicklung, Springer, Berlin Heidelberg

Eversheim, W.; \& Schuh, G. (2005). Integrierte Produkt- und Prozessgestaltung, Springer-Verlag, Heidelberg 
Gansauge, L. (2014). Methodik zur Industrialisierung der Einzelfertigung am Beispiel des Werkzeug- und Formenbaus, Technische Universität Chemnitz, Chemnitz

Göbel, M.; \& Teixeira, J. C. (2012). Graphics Modeling and Visualization in Science and Technology, springer, New York

Holl, J. (2003). Konzept zur Unternehmensplanung, -steuerung und -verwaltung durch objekt- und komponentenorientierte Entwicklung, Universität Duisburg - Essen, Duisburg

Hooshmand, Y.; Köhler, P.; \& Korff-Krumm, A. (2013, 2). Komplexitätsbeherrschung und Transparenzerhöhung in der Einzelfertigung, Produkt Daten Journal, pp. 55-59

Ising, M. (2001). System zur sicherheitsgerechten Konstruktion von Werkzeugmaschinen, IWF/TU Berlin, Berlin

Lingnau, V. (1994). Variantenmanagement: Produktionsplanung im Rahmen einer Produktdifferenzierungsstrategie, Erich Schmidt Verlag

Rogers, G.; \& Bottaci, L. (1997). Modular production systems: a new manufacturing paradigm, Journal of intelligent manufacturing, (pp. 147-156)

Schloter, W. (2003). Strategien zur Effizienzsteigerung von Konstruktion und Fertigung für einen optimierten Produktentwicklungsprozess im Sondermaschinenbau, Universität Essen, Büdingen

Schoenheit, M. (2013). Wirtschaftliche Prozeßgestaltung: Entwicklung Fertigung Auftragsabwicklung, Springer-Verlag, Köln

Schuh, G. (1989). Gestaltung und Bewertung von Produktvarianten: Ein Beitrag zur systematischen Planung von Serienprodukten, VDI, Düsseldorf

Shah, J.; Mäntylä, M.; \& Nau, D. (2013). Advances in Feature Based Manufacturing, Elsevier

Simpson, T. W.; Jiao, J.; Siddique, Z.; \& Hölttä-Otto, K. (2013). Advances in Product Family and Product Platform Design: Methods \& Applications, Springer Science \& Business Media

Tichkiewitch, S., Tollenaere, M., \& Ray, P. (2010). Advances in Integrated Design and Manufacturing in Mechanical Engineering II. Netherlands: Springer Science \& Business Media

Tietze, O. (2003). Strategische Positionierung in der Automobilbranche - Der Einsatz von virtueller Produktentwicklung und Wertschöpfungsnetzwerken, Deutscher Universitäts-Verlag, Wiesbaden

Weilguny, L. J. (2009). implementation of knowledge-based engineering conzept using feature technology at an automotive OEM. 17th International Conference on Engineering Design, Stanford University, Stanford, Kalifornien, USA

Will-Zocholl, M. (2011). Wissensarbeit in der Automobilindustrie: Topologie der Reorganisation von Ingenieursarbeit in der globalen Produktentwicklung, edition sigma, berlin

Zhao, X., \& Yu, K.-C. (2013). Research on ERP and PLM Integration Based on R\&D Project Management, In The 19th International Conference on Industrial Engineering and Engineering Management (pp. 1307-1313). Springer-Verlag, Berlin Heidelberg 